\title{
Identification of Circulating Natural Antibodies against Endogenous Mediators in the Peripheral Blood Sera of Patients with Osteoarthritis of the Knee: A New Diagnostic Frontier
}

\author{
Yulia A Savitskaya ${ }^{1 *}$, Carolina Duarte ${ }^{2}$, Norma Marín ${ }^{3}$, René Téllez ${ }^{4}$, Alfonso Alfaro ${ }^{5}$ and Clemente Ibarra ${ }^{1,6}$ \\ ${ }^{1}$ Tissue Engineering, Cell Therapy and Regenerative Medicine Unit, National Institute of Rehabilitation, Mexico City, Mexico \\ ${ }^{2}$ Department of Rheumatology, National Institute of Rehabilitation, Mexico City, Mexico \\ ${ }^{3}$ Department of Radiology, National Institute of Rehabilitation, Mexico City, Mexico \\ ${ }^{4}$ Department of Clinical Pathology, National Institute of Rehabilitation, Mexico City, Mexico \\ ${ }^{5}$ Department of Chromatography, National Institute of Rehabilitation, Mexico City, Mexico \\ ${ }^{6}$ Department of Sports Medicine and Arthroscopy, National Institute of Rehabilitation, Mexico City, Mexico
}

\begin{abstract}
Introduction: The presence of NA against EM regarding specificity and have gained increasing attention in proteome analysis for diagnosis, developing, monitoring and effective treatment of osteoarthritis of the knee $(\mathrm{kOA})$. An understanding of the various regulatory systems controlling blood vessel growth, inflammation and pain in the join should lead to help explain kOA disease progression. To investigate the specific presence of NA (IgM, $\operatorname{lgG}, \lg A)$ against EM (BK, AII, VEGF, bFGF) in the sera of kOA patients and control and to correlate this with process of joint destruction.
\end{abstract}

Methods: In this study novel immunoconjugates were designed, synthesized and then used to develop a rapid, specific and sensitive ELISA method to directly detect immune complexes (NA-EM) in humans. Following this procedure, we examined variations in the levels of natural antibodies recognized a panel of self-antigens in the sera from healthy individuals and kOA patients. Blood samples were obtained from 250 patients with symptomatic kOA and 250 ages, sex-matched healthy individuals.

Results: NA against EM was detected with novel ELISA assay in the sera of kOA patients as well as in the sera of control. At time of inclusion kOA patients $(100 \%)$ had significantly higher BK-lgG levels relative to normal sera. The over expression BK-lgG were positively associated with destructive changes ( $K L>4 ; r=0.75 ; p<0.005)$. KOA patients in whom KL scores progress rapidly tend to have higher BK-IgG levels at all time point. Serum BK-lgG over expression in KOA patients were positively associated with destructive changes $(K L>4 ; r=0.75 ; p<0.005)$. Elevated BK-IgG was significantly correlated with VAS $(r=0.85 ; p<0.0001)$ and loss of functions $(r=0.69 ; p<0.0003)$ in kOA patients. Affinity chromatography yielded EM-specific NA from the sera of healthy individuals and kOA patients.

Conclusions: We showed that EM represents a group of novel self-antigens which are targeted by NA from kOA patients. Circulating BK-IgG in the sera has been proposed as a sensitive and specific marker of diagnosing $\mathrm{kOA}$ at early stages of the disease. Our results have potential applications for controlling unwanted angiogenesis, inflammation, pain and future response to therapy in kOA patients.

Keywords: Osteoarthritis of the knee; Angiogenesis; Vasoregulatory systems; Inflammation; Pain; Radiological damage; immune regulation; Natural antibodies; Endogenous mediators; Serodiagnosis; Biomarkers

Abbreviations: ABTS: 2,20-Azino-Bis(3-Ethylbenzothiazoline6-Sulfonic Acid); AII: Angiotensin II; BFGF: Basic Fibroblast Growth Factor; BK: Bradykinin; BK-IgG: Natural IgG Antibodies against Bradykinin; BSA: Bovine Serum Albumin; CT: Computed Tomography; ELISA: Enzyme Linked Immunosorbentassay; EM: Endogenous Mediators; EM-IgG: Natural IgG Antibodies against Endogenous Mediators; HMW: High Molecular Weight; HAS: Human Serum Albumin; Ig: Immunoglobulin; IgA: Immunoglobulin A; IgAHRP: Immunoglobulin A-Horseradish peroxidase Conjugate; IgG: Immunoglobulin G; IgG-HRP: Immunoglobulin G-Horseradish Peroxidase Conjugate; IgM: Immunoglobulin $\mathrm{M}$; IgM-HRP: Immunoglobulin M-horseradish Peroxidase Conjugate; KL Grade: Kellgren-Lawrence grade; KKS: Kallikrein-kinin System; kOA: Osteo Arthritis of the knee; LMW: Low Molecular Weight; NA: Natural Antibodies; NHS: Normal Human Sera; OA: Osteoarthritis; PBS: Phosphate-Buffered Saline; PBST: phosphate-buffered saline with Tween20; RA: Rheumatoid Arthritis; RAS: Rennin-Angiotensin System; TMB: 3,3',5,5'-TetraMethylBenzidine; VAS: visual analogue scale; VEGF: Vascular Endothelial Growth Factor

\section{Introduction}

Osteoarthritis (OA) is the most common disorder affecting synovial joints, with structural changes of osteoarthritis present in approximately half of the adult population in world [1]. The knee is the most commonly affected weight-bearing joint and various deformity is the most common misalignment of the knee associated with osteoarthritis.

*Corresponding author: Yulia Anatolevna Savitskaya, Tissue Engineering Unit, Cellular Therapy and Regenerative Medicine, National Rehabilitation Institute, Calzada Mexico-Xochimilco 289, Colonia Guadalupe Arenal, Tlalpan, 14389 Postal Code, Mexico City, Mexico, Tel: (+52-55) 59991000; Fax: (+52-55) 56039015; Email: yulia.savitskaya2012@gmail.com

Received April 24, 2012; Accepted October 27, 2012; Published October 30, 2012

Citation: Savitskaya YA, Duarte C, Marín N, Téllez R, Alfaro A, et al. (2012) Identification of Circulating Natural Antibodies against Endogenous Mediators in the Peripheral Blood Sera of Patients with Osteoarthritis of the Knee: A New Diagnostic Frontier. J Mol Biomark Diagn 3:135. doi:10.4172/2155-9929.1000135

Copyright: (C) 2012 Savitskaya YA, et al. This is an open-access article distributed under the terms of the Creative Commons Attribution License, which permits unrestricted use, distribution, and reproduction in any medium, provided the original author and source are credited 
Osteoarthritis of the knee $(\mathrm{kOA})$ can be a progressive disabling disease, which results from the pathological imbalance of degradative and reparative processes, with concomitant inflammatory changes [2]. The clinical features of $\mathrm{kOA}$ include pain, stiffness, reduced motion, swelling, crepitus, and deformity [3-5].

Several factors are considered for the pathogenesis of $\mathrm{kOA}$ [614]. Complicated path biological interactions between the KallikreinKinin System (KKS), the Rennin-Angiotensin (RAS), angiogenesis and natural immunity could contribute to joint destruction in the disease process of $\mathrm{kOA}$ [15-19]. It is also likely that biomarkers will be used in conjunction with imaging in order to establish stage of disease, predict progression, and assess improvement in the setting of clinical trials [20-22].

Vasoregulatory systems are developed and a fully functional microvasculature is formed in $\mathrm{kOA}[6,19,23,24]$. Vasoregulatory systems, as the KKS and the RAS, play essential roles in the maintenance of vascular homeostasis $[25,26]$. An understanding of the various regulatory systems controlling blood vessel growth, inflammation and pain in the joint should lead to help explain kOA progression.

The KKS, most well-known as mediator of inflammation, also has role in the control of vessel diameter and growth $[27,28]$. Factors of KKS are thought to be key mediators in inflammatory joint disease [3]. Kinins released into synovial fluid by the proteolytic action of kallikreins on kininogens on the surface of neutrophils are likely to cause vasodilatation and pain, increase vascular permeability, promote leukocyte margination and stimulate cytokine release from monocytes $[17,29]$. Pain, the predominant symptom in $\mathrm{kOA}$, is multidimensional in its nature and mediated through a variety of factors as bradykinin [30-33].

The RAS is best known as a major regulator of blood pressure, but it also is important at the micro vascular level in the regulation of neovascularization [34,35]. In addition, the RAS has important modulatory activities in the process of $\mathrm{kOA}$ [24]. Vascular inflammation is an independent risk factor for the development of $\mathrm{kOA}$ [19]. Angiotensin II (AII) augments vascular inflammation, induces endothelial dysfunction, and, in so doing, enhances the process of $\mathrm{kOA}$ [25]. AII the classical signs of inflammation-pain, redness, erythema, edema, and hyperthermia.

Angiogenesis, defined as the development of new capillaries from preexisting blood vessels, is an important the pathogenesis of $\mathrm{kOA}$ since it in the initiation and perpetuation of the disease $[2,18]$. Inflammation and angiogenesis are closely associated in $\mathrm{kOA}$, modulating functions of chondrocytes, contributing towards abnormal tissue growth and perfusion, ossification and endochondral bone towards abnormal tissue growth and perfusion, ossification and endochondral bone development, leading to radiographic changes observed in the joint [36-39].

Almost all of the human autoimmune diseases are characterized by the generation of Natural Antibodies (NA) [40-44]. Identifying those antibodies is the cornerstone for the diagnosis of autoimmunity in humans [45-50]. In autoimmune rheumatic diseases, pathogenic auto antibodies are used for classification, development of diagnostic criteria, monitoring of disease activity and prediction of prognosis [51-53]. However, autoimmunity defined by the detection of auto antibodies does not necessarily imply the presence of an autoimmune disease. Furthermore, the normal immune system is able to produce, in relatively high amounts, antibodies that bind various self-antigens, i.e. endogenous mediators. Those auto antibodies, defined as NA, have an important physiological regulatory role [54-57].

NA refers to antibodies that are present in the serum of healthy individuals in the absence of deliberate immunization with the target antigen [58,59]. A vast majority of NA react with one or more self antigens and are termed as natural auto antibodies [60,61]. The importance of NA in immune regulation has long been neglected, since tolerance to self was thought to be primarily dependent on the deletion of auto reactive clones, rather than on peripheral suppressive mechanisms [62,63]. Clonal deletion and energy cannot account, however, for the prevalence of natural auto reactivity among healthy individuals [64]. It is now well established that auto reactive antibodies and $\mathrm{B}$ cells, and auto reactive $\mathrm{T}$ cells, are present in healthy individuals, and in virtually all vertebrate species [65]. Auto reactive repertoires are predominantly selected early in ontogeny $[66,67]$. Questions pertaining to the role of NA in the regulation of the immune response and maintenance of immune homeostasis and to the distinction between natural auto reactivity and pathological autoimmunity have not been adequately addressed $[68,69]$.

$\mathrm{KOA}$ is a chronic, destructive autoimmune disease of the joints $[9,70,71]$. It is characterized by the presence of NA that are reactive to various target molecules [72-76]. $\mathrm{kOA}$ is an autoimmune disease characterized by chronic synovitis, which manifests as joint pain and often progresses to bone and joint destruction [77-81]. Inflammation in $\mathrm{kOA}$ may result from a number of different mechanisms, including antibody-mediated complement activation and cellular injury, T-cellmediated mechanisms and generation of pro-inflammatory mediators $[82,83]$.

Differentiating between pathogenic, natural and other nonpathogenic auto antibodies is crucial for the definition, diagnosis and identification of a reliable biomarker of osteoarthritis [84-87] The identification of NA that highly predicts the development of $\mathrm{kOA}$ is of great interest. This study focuses on human NA against EM discovered in our Unit $[88,89]$. Development technologies that permit assessment of potentially disease-modifying agents of vascularization and inflammation are the current approach to the management of kOA. It is an established fact that any physiological stress can interact with the immune system.

The analysis of the osteoarthritis-associated antigen-antibody systems in the normal peripheral blood has new approach to the patient at risk for or with newly diagnosed $\mathrm{kOA}$. The presence of NA against EM regarding specificity and have gained increasing attention in proteome analysis for diagnosis, developing, monitoring and effective treatment of kOA. Previous retrospective studies in different countries have shown that NA can be detected in patients with $\mathrm{kOA}$ several years before clinical symptoms occur [57,90-93]. Given the low prevalence of $\mathrm{kOA}$, NA testing in the general population is of no clinical benefit. $\mathrm{NA}$ in $\mathrm{kOA}$ has been found to be quite useful in clinical practice for diagnosis and assessing prognosis. NA against EM has recently been shown to predict development of $\mathrm{kOA}$ as well as poor outcome in early kOA.

The aim of this study was to investigate the specific presence of NA (IgM, IgG, and IgA) against EM (bradykinin, angiotensin II, vascular endothelial growth factor, basic fibroblast growth factor) in the peripheral blood sera of patients with o $\mathrm{kOA}$ and healthy individuals. In addition, we are interested in investigating the functional properties of affinity-isolated NA against EM from the peripheral blood of healthy individuals and patients with $\mathrm{kOA}$ (focusing on isotype, affinity, 
Citation: Savitskaya YA, Duarte C, Marín N, Téllez R, Alfaro A, et al. (2012) Identification of Circulating Natural Antibodies against Endogenous Mediators in the Peripheral Blood Sera of Patients with Osteoarthritis of the Knee: A New Diagnostic Frontier. J Mol Biomark Diagn 3:135. doi:10.4172/2155-9929.1000135

Page 3 of 9

specificity). This study also further characterizes the markers of clinical relevance in patients with $\mathrm{kOA}$.

\section{Methods}

\section{Patients}

The study included 250 patients with symptomatic kOA (age range 45-79 years) fulfilling the American College of Rheumatology criteria for kOA. All patients with kOA had involvement of the knee joint with typical radiographic changes graded Kellgren Lawrence classification. Pain was scored on a Visual Analogue Scale (VAS) immediately after walking $50 \mathrm{~m}$. All patients with $\mathrm{kOA}$ are with persistent pain longer than 6 months. Parameters for function were performed by Lequesne's functional indexes. 250 age and sex-matched healthy Individuals. Characteristics of patients are listed in (Table 1). The patients and control had no associated organic disease and exhibited no evidence of autoimmune disease. They did not have immunological or other arthritic disease or any physical illness known to affect their immunological status.

\section{Control subjects}

The general reference (normal) control samples consisted in ageand sex-matched 250 healthy individuals in Blood Transfusion Service of the National Institute of Rehabilitation (Mexico City, Mexico). The absence of disease was confirmed by physical examination, clinical history and routine laboratory tests.

\section{Blood sampling}

Seven milliliters of the peripheral blood was drawn into a serum separator tube (Vacutainer Systems, code 607213 Becton-Dickinson, USA). Blood was allowed to clot for $1 \mathrm{~h}$ at Room Temperature (RT). Sera were obtained after centrifugation at $3000 \mathrm{rpm}$ for $10 \mathrm{~min}$ at $4^{\circ} \mathrm{C}$. All serum samples were stored in $300 \mu$ aliquots at $-80^{\circ} \mathrm{C}$ until analysis.

\section{Reagents}

All reagents were of analytical grade and were obtained from Sigma-Aldrich Ltd, Poole, UK, unless otherwise indicated.

\section{Design and synthesis of immunoconjugates for ELISA}

In this study novel immunoconjugates were designed, synthesized and then used to develop a rapid, specific and sensitive ELISA method to detect NA against EM directly in the peripheral venous blood sera of humans. Human low molecular weight EM was coupled with High Molecular Weight Matrix (HMWM: polyphenylacrilate) according to in-hous protocols provided by Tissue Engineering, Cell Therapy and Regenerative Medicine Unit (National Institute of Rehabilitation, Mexico City, Mexico). Briefly, $1 \mathrm{mg}$ of HMWM was coupled to $1 \mathrm{mg}$ of $\mathrm{EM}$ in $0.1 \mathrm{M}$ buffer, $\mathrm{pH} 4.5$, containing $2 \mathrm{mg}$ of EDC in a final volume of $1.6 \mathrm{ml}$. The mixture was incubated for $2 \mathrm{~h}$ at RT. The conjugated EM-

\begin{tabular}{|c|c|c|}
\hline VARIABLES & OA & CONTROL \\
\hline Age (years) & $54 \pm 8.8$ & $51 \pm 11.1$ \\
\hline Body mass index BMI (kg/m2) & $26 \pm 2.5$ & $26 \pm 3.3$ \\
\hline Duration of OA (years) & $13.0 \pm 9.8$ & \\
\hline Pain (visual analog) scores & $5.46 \pm 2.15$ & $0.00 \pm 0.00$ \\
\hline Beck Depression Index & $5.56 \pm 5.69$ & $1.00 \pm 1.86$ \\
\hline $\begin{array}{l}\text { Mean interval in years } \\
\text { between baseline and follow-up } \\
\text { scan }\end{array}$ & 2.67 & \\
\hline
\end{tabular}

Table 1: Baseline characteristics of study population.

\begin{tabular}{|l|l|l|l|l|}
\hline \multicolumn{1}{|c|}{$\%$} & \multicolumn{5}{|c|}{ SELF ANTIGEN } \\
\hline & BK & All & VEGF & bFGF \\
\hline Reproducibility & 96 & 97 & 90 & 90 \\
\hline Sensitivity & & & & \\
\hline Primary kOA & 26 & 13 & 23 & 8 \\
\hline Secondary kOA & 17 & 8 & 5 & 3 \\
\hline Specificity & 96 & 95 & 93 & 91 \\
\hline
\end{tabular}

Table 2: Reproducibility, sensitivity and specificity of detection of natural IgG antibodies in osteoarthritis of the knee.

HMWM was then dialyzed against Phosphate Buffered Saline (PBS), $\mathrm{pH} 7.4$ at $4^{\circ} \mathrm{C}$.

\section{Development of ELISA for rapid detection natural antibodies against endogenous mediators}

Polystyrene micro titer ELISA plates with 96-wells (Maxi-sorb, NUNC, Rochester, NY, USA) were incubated overnight at $4^{\circ} \mathrm{C}$ with EM-HMWM $(1 \mu \mathrm{g} / \mathrm{ml})$ in $0.1 \mathrm{M}$ carbonate/bicarbonate buffer, $\mathrm{pH}$ 9.6. The final volume of this as well as of all other steps was $100 \mu \mathrm{l}$ per well, unless stated otherwise. After washing the plates twice with PBS, residual binding sites were blocked ( $1 \mathrm{~h}$ at RT) with $200 \mu \mathrm{l}$ per well of PBS containing $2 \%$, w/v, Human Serum Albumin (HAS). Human sera were appropriately diluted in assay buffer (veronal buffer containing $0.1 \%$, w/v, HSA, $2 \mathrm{mM} \mathrm{CaCl}_{2}, 0.1 \%$, w/v, Tween-20, pH 7.4), and, incubated for $1 \mathrm{~h}$ at RT. After this and the subsequent incubation steps, the plates were washed with PBS containing $0.1 \%$, w/v, Tween- 20 (PBST). IgM, IgG, IgA bound to EM-HWMM was quantified with horseradish peroxidase labeled anti-human IgM, IgG, IgA diluted in assay buffer. Finally, horseradish peroxidase activity was visualized by

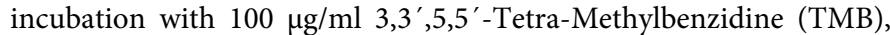
in $0.11 \mathrm{M}$ sodium acetate, $\mathrm{pH} 5.5$, containing $0.003 \%, \mathrm{v} / \mathrm{v}, \mathrm{H}_{2} \mathrm{O}_{2}$. The reaction was stopped after 10 min by addition of $2 \mathrm{M} \mathrm{H}_{2} \mathrm{SO}_{4}$, and the absorbance at $450 \mathrm{~nm}$ was measured in a micro titer plate reader (BioKinetics Reader; Bio-Tek Instruments, Winooski, VT, USA). Tests were performed in duplicate. All measurement (patients and control subjects) were made on the same day and under the same experimental conditions.

Dilutions of a pool of normal sera, obtained from 250 healthy volunteers, were used to generate a standard curve in each micro titer plate. This standard was arbitrarily proposed to contain EM-Ig. Results with serum samples were related to this standard and expressed as EM-Ig. The specificity of the binding of EM-Ig to EM-HWMM was determined by competition immunoassay (Table 2). The standard curve was pre-incubated with increasing amounts of the competitors. After $1 \mathrm{~h}$ incubation, the standard with or without competitors was added to the EM-HWMM-coated plates and tested as described above.

\section{Purification of human natural antibodies against endogenous mediators}

Immunoabsorbent columns were prepared with antigen of interest coupled to cyanogens bromide-activated Sepharose (Pharmacia Biotech). Two milligrams of protein were used for coupling to $1.5 \mathrm{ml}$ of bed volume of CNBr-activated Sepharose.

One gram of Ig in $100 \mathrm{ml}$ of PBS was loaded on the immunoadsorbent column and run twice on the column at a speed of $1 \mathrm{ml} / \mathrm{min}$ at RT, followed by washing with PBS until the absorbance of the flow-through at $280 \mathrm{~nm}$ reached baseline values. Bound antibodies were eluted using glycine- $\mathrm{HCl}(0.1 \mathrm{M})$ buffer of $\mathrm{pH} 2.8,2 \mathrm{M} \mathrm{NaCl}$ followed by PBS and then diethanolamine $(0.1 \mathrm{M})$ buffer, $\mathrm{pH} 11 ; 2 \mathrm{M} \mathrm{NaCl}$. The eluates obtained at different $\mathrm{pH}$ were brought to $\mathrm{pH} 7.0$ and pooled. Two 
Citation: Savitskaya YA, Duarte C, Marín N, Téllez R, Alfaro A, et al. (2012) Identification of Circulating Natural Antibodies against Endogenous Mediators in the Peripheral Blood Sera of Patients with Osteoarthritis of the Knee: A New Diagnostic Frontier. J Mol Biomark Diagn 3:135. doi:10.4172/2155-9929.1000135

Page 4 of 9

milliliters of the flow-through fractions were allowed to run through the sorbents for two more cycles and further used as effluent fractions. Eluates and effluents were dialyzed against PBS.

\section{Affinity of purification of natural antibodies against endog- enous mediators}

Immunoabsorbent columns were prepared with the antigens of interest coupled with cyanogens bromide-activated Sepharose (Pharmacia Biotech) [94,95]. One milligram of protein was used for coupling with $1.5 \mathrm{ml}$ of bed volume of $\mathrm{CNBr}$-activated Sepharose. One gram of IVIG in $100 \mathrm{ml}$ of PBS was loaded on the immunoadsorbent column and run twice on the column at a speed of $1 \mathrm{ml} / \mathrm{min}$ at RT, followed by washing with PBS until the absorbance of the flow-through at $280 \mathrm{~nm}$ reached baseline values. Bound antibodies were eluted using a glycine- $\mathrm{HCl}(0.1 \mathrm{M})$ buffer, $\mathrm{pH} 2.8$ and $2 \mathrm{M} \mathrm{NaCl}$ followed by PBS and then diethanolamine $(0.1 \mathrm{M})$ buffer, $\mathrm{pH} 11 ; 2 \mathrm{M} \mathrm{NaCl}$. The eluates obtained at different $\mathrm{pH}$ levels were brought to $\mathrm{pH} 7.0$ and pooled. Two milliliters of the flow-through fractions were allowed to run through the sorbents for two more cycles and then used as effluent fractions. Eluates and effluents were dialyzed against PBS.

\section{Determination of total IgM and IgG levels}

We used the CovaLink ELISA system to determine the total IgM and IgG levels of the patients and controls. For each plate standard curves were drawn using known amounts of no conjugated human IgG and IgM.

\section{Radiological method}

Plain X-ray films were performed on the small joints of the knee in all osteoarthritis patients at baseline $(n=250)$ and after two years $(n=250)$. These films were examined by expert radiologists. Radiological progression was defined as an increase in the LS score from the baseline to endpoint that was greater than the median value for each patient. The Kellgren-Lawrence (KL) grade, an integer index ranging from 0 to 4 , is a standard radiographic measurement of joint degradation used in diagnosing osteoarthritis of the knee [96]. Radiographic osteoarthritis can be defined simply as a KL grade of 2 or higher.

\section{Statistical analysis}

The data was analyzed on an IBM computer using SPSS. Quantitative variables were described as mean, standard deviation (SD) and range. Qualitative variables were described as number and percentage. The Chi-square test was used to compare qualitative variables between groups. The Kruskal-Wallis test was used instead of ANOVA in non-parametric data (SD $>50 \%$ mean). Spearman's correlation test was used to rank different variables against each other. Receiver Operator Characteristic Curve (ROC) was drawn to find out the best cut-off value of natural antibodies against endogenous mediators in diagnosing osteoarthritis of the knee and to test for its statistical efficacy. P-value $>0.05$ was considered insignificant, $\mathrm{p}<0.05$ was significant and $\mathrm{p}<0.01$ was highly significant.

\section{Ethical approval}

All patients and healthy controls provided informed, written consent and the study was approved by the Ethics Committee of National Institute of Rehabilitation, Mexico City, Mexico.

\section{Results}

Serological identification of natural antibodies against endogenous mediators in healthy Individuals and patients with osteoarthritis of the knee by the novel ELISA Natural self-reactive antibodies of the IgM, IgG and IgA isotype are present in the serum of healthy individuals and kOA patients. Different classes of NA (IgM, IgG, IgA) against EM (BK, ANII, VEGF, bFGF) were detected with novel ELISA protocol in the sera of $\mathrm{kOA}$ patients as well as in the sera of healthy individuals (Table 3). These EM represent a group of novel self antigens which are targeted by NA from kOA patients.

In this study, we found BK-IgG expression most abundantly in testis among the kOA sera tested. No significant difference in binding of serum EM-IgA levels in $\mathrm{kOA}$ patients in comparison with that in control. Characterization of the functional properties of natural antibodies that recognize human endogenous mediators.

\section{Isotypes of natural antibodies against endogenous mediators}

NA belong mainly to the immunoglobulin $M$ class and are characterized by several features, including the ability to bind self and non-self antigens, low affinity (monovalent antigenic binding to a small single epitope), high avidity (overall force that binds multivalent antibody to a macromolecule carrying multivalent epitopes), and polyreactivity (binding different epitopes). Pathogenic auto antibodies are antigen driven and belong mainly to the IgG isotype. Affinity chromatography yielded two isotypes (IgM, IgG) of EM-specific NA from the sera of healthy individuals and $\mathrm{kOA}$ patients. EM-IgA was not useful for the presence kOA in humans. Affinity-purified NA against EM displayed the expected characteristics and was functionally fully active.

\section{Affinity of natural antibodies against endogenous mediators}

The affinity constant of NA against self-antigens from both $\mathrm{kOA}$ patients and normal sera were determined in table 4. Low affinity EM-IgM was predominantly isotype of Ig which present in healthy individuals. Deficiency in the sera EM-IgM predisposes to development expression of high affinity EM-IgG in kOA patients. The secondary immune response is characterized by the rapid production of high affinity EM-IgG in kOA patients.

\begin{tabular}{|c|c|c|c|c|c|c|c|c|}
\hline \multirow[t]{4}{*}{ The Study Group } & \multicolumn{8}{|c|}{ Self Antigens } \\
\hline & \multicolumn{2}{|c|}{ BK } & \multicolumn{2}{|c|}{ All } & \multicolumn{2}{|c|}{ VEGF } & \multicolumn{2}{|c|}{ bFGF } \\
\hline & \multicolumn{8}{|c|}{ ISOTYPE of NATURAL ANTIBODIES } \\
\hline & $\lg \mathbf{G}$ & IgM & IgG & $\lg M$ & IgG & $\lg M$ & $\lg G$ & IgM \\
\hline \multirow{2}{*}{$\begin{array}{l}\text { Patients with osteoarthritis } \\
\text { of the knee }\end{array}$} & $689 \pm 161$ & $287 \pm 84$ & $409 \pm 111$ & $289 \pm 99$ & $669 \pm 241$ & $559 \pm 198$ & $689 \pm 245$ & $521 \pm 222$ \\
\hline & $100 \%$ & $77 \%$ & $71 \%$ & $66 \%$ & $59 \%$ & $79 \%$ & $35 \%$ & $61 \%$ \\
\hline Healthy Individuals & $501 \pm 98$ & $407 \pm 115$ & $274 \pm 84$ & $455 \pm 101$ & $471 \pm 189$ & $366 \pm 181$ & $455 \pm 115$ & $705 \pm 239$ \\
\hline Significance $P$ value & 0.0001 & 0.0004 & 0.0005 & 0.0001 & 0.0003 & 0.005 & 0.009 & 0.007 \\
\hline
\end{tabular}

Table 3: Serum expression of natural antibodies against endogenous mediators 
Citation: Savitskaya YA, Duarte C, Marín N, Téllez R, Alfaro A, et al. (2012) Identification of Circulating Natural Antibodies against Endogenous Mediators in the Peripheral Blood Sera of Patients with Osteoarthritis of the Knee: A New Diagnostic Frontier. J Mol Biomark Diagn 3:135. doi:10.4172/2155-9929.1000135

Page 5 of 9

\begin{tabular}{|l|l|l|l|l|l|l|}
\hline \multirow{2}{*}{$\begin{array}{l}\text { The Study } \\
\text { Group }\end{array}$} & \multicolumn{3}{|c|}{ VEGF } & \multicolumn{2}{c|}{ BK } & \multicolumn{2}{c|}{ All } \\
\cline { 2 - 6 } & \multicolumn{2}{|c|}{ AFFINITY CONSTANTS RANGING BETWEEN, M } \\
\cline { 2 - 6 } IgM & IgG & IgM & IgG & IgM & IgG \\
\hline $\begin{array}{l}\text { Healthy } \\
\text { Individuals }\end{array}$ & $10^{-6}-10^{-7}$ & $10^{-5}-10^{-8}$ & $10^{-6}-10^{-7}$ & $10^{-5}-10^{-8}$ & $10^{-6}-10^{-8}$ & $10^{-5}-10^{-7}$ \\
\hline $\begin{array}{l}\text { Patients with } \\
\text { osteoarthritis } \\
\text { of the knee }\end{array}$ & $10^{-10}-10^{-11}$ & $10^{-4}-10^{-6}$ & $10^{-9}-10^{-11}$ & $10^{-3}-10^{-5}$ & $10^{-9}-10^{-10}$ & $10^{-4}-10^{-5}$ \\
\hline
\end{tabular}

Table 4: The affinity of natural antibodies against endogenous mediators from both osteoarthritis of the knee and normal sera.

\begin{tabular}{|l|l|l|l|l|}
\hline $\begin{array}{l}\text { Structurally \% } \\
\text { Significant Inhibition } \\
\text { Similar Inhibitors }\end{array}$ & \multicolumn{4}{|c|}{ \% Significant Inhibition } \\
\cline { 2 - 5 } & BK-IgG & BK-IgM & All-IgG & All-IgM \\
\hline Angiotensin II & 0.12 & 0.01 & 100 & 100 \\
\hline Bradykinin & 100 & 100 & 0.02 & 0.01 \\
\hline Vasopressin & 0.003 & 0.01 & 0.07 & 0.001 \\
\hline Dermorphin & 0.001 & 0.001 & 0.003 & 0.001 \\
\hline Beta-Endorphin & 0.007 & 0.001 & 0.001 & 0.02 \\
\hline
\end{tabular}

Table 5: The cross-reactivity of affinity-purified natural antibodies agains endogenous mediators from osteoarthritis of the knee and normal sera.

\begin{tabular}{|l|l|l|}
\hline Variables & Spearman's $\mathbf{r}$ & $\mathbf{P}$ \\
\hline BK-IgG & 0.897 & 0.0005 \\
\hline All-IgG & 0.489 & 0.0027 \\
\hline VEGF-IgG & 0.381 & 0.0045 \\
\hline bFGF-lgG & 0.291 & 0.0001 \\
\hline
\end{tabular}

Table 6: Correlations between Kellgren Lawrence grading and serum markers.

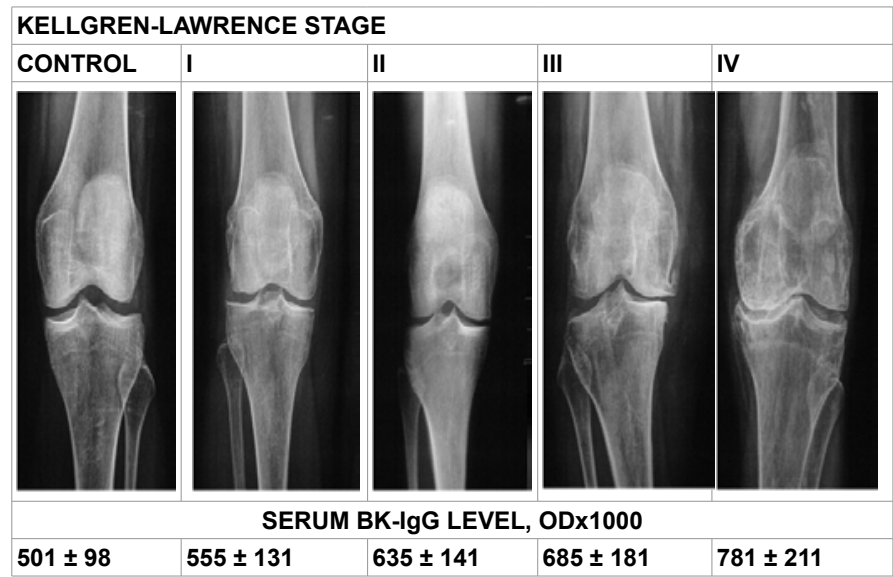

Table 7: Correlations of bk-lgG titer with kellgren-lawrence grading.

Specificity of natural antibodies against endogenous mediators

The cross-reactivity of affinity-purified natural antibodies against selfantigens from both $\mathrm{kOA}$ and normal sera were determined (Table 5). Serum BK-IgG was detectable in $85 \%$ of kOA patients, with $100 \%$ specificity for kOA. NA against BK and AII showed no cross reactivity to other structurally similar EM.

Natural antibodies against endogenous mediators in relation to radiographic progression assessed by Kellgren-Lawrence scoring the many measurable outcomes in OA include pain, function, synovitis, and serum and urine biomarkers or imaging biomarkers. Currently, radiographic outcomes are used to establish diagnosis and follow structural progression of the disease. While current radiographic techniques (X-rays) are useful for the diagnosis of established disease, they have shortcoming with respect to the assessment of progressive disease.

Radiographic impairment was assessed by Kellgren-Lawrence score at baseline and again after 2 years. The mean Kellgren-Lawrence score in the whole group at presentation was 2.5 and the mean progression was 4 . The relationship between the Kellgren-Lawrence grading and serum markers is also shown in table 6 .

A significant relationship was noted for BK-IgG (Table 7). We examined associations between serum BK-IgG and radiographic KOA status. Levels of serum BK-IgG were positively associated with all definitions of radiographic $\mathrm{kOA}(\mathrm{p}<0.0001)$. KOA Patients in whom KL scores progress rapidly tend to have higher serum BK-IgG levels at all time point. Serum BK-IgG Over expression in $\mathrm{kOA}$ patients were positively associated with destructive changes $(\mathrm{KL}>4 ; \mathrm{r}=0.75 ; \mathrm{p}<0.005)$. No correlations were found to conventional parameters for pain and function with expression of NA (isotypes $\operatorname{IgA}$, IgM) against EM.

Table 8 shows the correlations between the serum markers in all of the subjects as determined by the Spearman rank test. These were significant correlations between BK-IgG and VEGF-IgG, between bFGF-IgG and VEGF-IgG, and between BK-IgG and AII-IgG. Table 9 shows the correlations between the joint space width and endogenous markers. All markers had negative correlations with the joint space width, but only serum BK-IgG had a significant correlation $(\mathrm{p}<0.0005)$.

\section{Discussion}

Diagnostic immunology is a collective term for a variety of diagnostic techniques that rely on the specificity of the bond between antibodies and antigens [97-100]. The pathologic role of natural antibodies in many autoimmune diseases is widely accepted [101103]. Clinically detectable joint inflammation may predict a worse radiological outcome in osteoarthritis of the knee [104-106].

Immunoassays are of general interest for all proteomic and diagnostic approaches in which several parameters have to be determined simultaneously from a limited amount of sample material. Improved analytical methods are required to accommodate the analysis of large numbers of samples for biological and epidemiological monitoring [44,107-112]. A sensitive assay to identify markers that can accurately determine the onset of osteoarthritis-especially if the technique is of low risk to the patient, such as blood drawing -is ideal for early detection of osteoarthritis of the knee. An enzyme immunoassay was used for measurement of antibodies against diseasespecific antigens and etiologic agents for cross-reactive antigens associated with them. This natural antibodies assay was applied to a panel of antigens for the detection of osteoarthritis of the knee. Novel

\begin{tabular}{|c|c|c|c|c|}
\hline Marker & BK-lgG & All-IgG & VEGF-IgG & bFGF-IgG \\
\hline BK-lgG & - & & 0.855 & \\
\hline All-IgG & 0.881 & - & & 0.293 \\
\hline VEGF-IgG & & 0.213 & - & \\
\hline bFGF-IgG & & & 0.791 & - \\
\hline
\end{tabular}

Table 8: Correlations between natural antibodies.

\begin{tabular}{|l|l|l|}
\hline Variables & Spearman's $\mathbf{r}$ & $\mathbf{P}$ \\
\hline BK-IgG & 0.897 & 0.0005 \\
\hline All-IgG & 0.489 & 0.0027 \\
\hline VEGF-IgG & 0.381 & 0.0045 \\
\hline bFGF-lgG & 0.211 & 0.0001 \\
\hline
\end{tabular}

Table 9: Correlations between joint space width and markers. 
Citation: Savitskaya YA, Duarte C, Marín N, Téllez R, Alfaro A, et al. (2012) Identification of Circulating Natural Antibodies against Endogenous Mediators in the Peripheral Blood Sera of Patients with Osteoarthritis of the Knee: A New Diagnostic Frontier. J Mol Biomark Diagn 3:135. doi:10.4172/2155-9929.1000135

antigen-specific ELISA will be used in additional studies that will prove its clinical efficacy, not only for the early diagnosis osteoarthritis of the knee, but also for prognosis and the implementation of preventive steps for osteoarthritis of the knee.

Natural antibodies, which bind self-protein as endogenous mediators, are keys to the homeostasis of the immune system, particularly relating to B-lymphocytes and autoimmunity [113116]. Serological evidence of the presence natural antibodies against endogenous mediators is an early future in osteoarthritis of the knee and not restricted to patients with end-stage disease undergoing joint replacement surgery. An understanding of the properties of natural antibodies, which characterizes their activity in relation to selfantigens, is important for binding capacity, functional activities, and immune recognition.

In this first study, we demonstrate the presence of natural polyreactive antibodies in normal human IgG that recognize bradykinin. Natural self-reactive antibodies belong to IgM, IgG and IgA isotypes. Here we found that natural IgG antibodies to bradykinin are predominantly of the IgG isotype. This may be of interest in view of previous findings indicating that natural antibodies specific for bradykinin in healthy individuals are of IgM class, while in patients osteoarthritis of the knee they are mostly IgG.

Kinins are thought to be key mediators in inflammatory joint disease. Bradykinin may exert influence on multiple players of the immune system. Bradykinin modulates the activation, proliferation, migration and effectors functions of these cells. The possible impact of bradykinin in human immune-mediated diseases could be emphasis on autoimmune neuroinflammation, osteoarthritis and infection. However, recent studies suggest a specific role of the bradykinin system in adaptive, i.e., antigen-specific immune reactions. Expression patterns of the bradykinin receptors on key cellular players within the adaptive immune system, and provide an overview of evidence so far indicating the possible involvement of the Kallikrein-kinin system in antigenspecific immune responses, including osteoarthritis conditions.

In healthy patients, chronic elevations of circulating BK-IgG or its biomarkers are predictors for increased risk in the development and progression of osteoarthritis of the knee disease. Predicting disease requires specific tests as well as a population in which a reasonable proportion of patients will develop disease [117]. The presence of BKIgG was an important predictor for osteoarthritis of the knee.

In the present work we have shown that all IgM anti-EM antibodies and certain IgG-type anti-EM antibodies were significantly elevated in sera of patients with osteoarthritis of the knee compared with adult controls. Serum anti-EM antibody ratios were consistently low for IgM antibodies and were relatively high in the case of IgGs. In contrast to $\operatorname{IgM}, \operatorname{IgG}$ gets into the inflamed synovial fluid readily, and thus, our data argue against local production of IgM type anti-EM antibodies.

The next important step was to test if the levels of BK-IgG antibodies showed any correlation with the disease activity in osteoarthritis of the knee. Intriguingly, using a multistep approach, our work has demonstrated that BK-specific IgG antibody levels show a clear inverse correlation with the activity of osteoarthritis of the knee. Thus, we suggest that BK-specific IgG is a disease-state biomarker in osteoarthritis of the knee. We found a similar relation when we analyzed the connection between disease activity and BK-IgG concentrations.

\section{Conclusions}

We showed that novel ELISA assay was able to demonstrate immune responses to each of the 4 type specific self-antigens in kOA patients. EM represents a group of novel self-antigens which are targeted by NA from kOA patients. Self-reactive NA of IgM, IgG, IgA classes are present in the sera of healthy individuals and kOA patients. This results show a specific imbalance of immunoglobulin's content in $\mathrm{kOA}$ patients. Serum NA profiling is a promising approach for early detection and diagnosis of kOA. Additionally, a serum expression profiling study identified 4 self-antigens specifically expressed in kOA patients, which were identified by affinity chromatography. High-affinity, BK-IgG has demonstrated a direct role for $\mathrm{BK}$ in $\mathrm{kOA}$ development. The isolated IgG fractions of patients suffering from $\mathrm{kOA}$ had higher anti-BK reactivity than those detected in normal individuals. Serum BK-IgG is a promising candidate as $\mathrm{kOA}$-specific disease antibodies. Identification of novel broadly cross-reactive $\mathrm{kOA}$ neutralizing NA against EM in the sera has major implications for the development of treatment, angiogenesis inhibitors, and tools to study mechanisms.

\section{Acknowledgements}

This work was supported by a grant from FONSEC SSA/IMSS/ISSSTECONACyT (grant SALUD-2010-01-138883 to Y.A.S.)

\section{References}

1. Krasnokutsky S, Samuels J, Abramson SB (2007) Osteoarthritis in 2007. Bul NYU Hosp Jt Dis 65: 222-228.

2. Bodolay E, Koch AE, Kim J, Szegedi G, Szekanecz Z (2002) Angiogenesis and chemokines in rheumatoid arthritis and other systemic inflammatory rheumatic diseases. J Cell Mol Med 6: 357-376.

3. Couture R, Harrisson M, Vianna RM, Cloutier F (2001) Kinin receptors in pain and inflammation. Eur J Pharmacol 429: 161-176.

4. Rittner HL, Brack A, Stein C (2002) Pain and the immune system: friend or foe? Anaesthesist 51: 351-358.

5. Yuan GH, Masuko-Hongo K, Kato T, Nishioka K (2003) Immunologic intervention in the pathogenesis of osteoarthritis. Arthritis Rheum 48: 602-611.

6. Cassim B, Shaw OM, Mazur M, Misso NL, Naran A, et al. (2009) Kallikreins kininogens and kinin receptors on circulating and synovial fluid neutrophils: role in kinin generation in rheumatoid arthritis. Rheumatology (Oxford) 48: 490-496.

7. Cohen IR (2007) Biomarkers, self-antigens and the immunological homunculus J Autoimmun 29: 246-249.

8. Fernandes JC, Martel-Pelletier J, Pelletier JP (2002) The role of cytokines in osteoarthritis pathophysiology. Biorheology 39: 237-246.

9. György B, Tóthfalusi L, Nagy G, Pásztói M, Géher P, et al. (2008) Natura autoantibodies reactive with glycosaminoglycans in rheumatoid arthritis. Arthritis Res Ther 10: R110.

10. Jones V, Taylor PC, Jacoby RK, Wallington TB (1984) Synovial synthesis of rheumatoid factors and immune complex constituents in early arthritis. Ann Rheum Dis 43: 235-239.

11. Koch B, Locher P, Burmester GR, Mohr W, Kalden JR (1984) The tissue architecture of synovial membranes in inflammatory and non-inflammatory join diseases. II. The localization of mononuclear cells as detected by monoclonal antibodies directed against T-lymphocyte subsets and natural killer cells. Rheumatol Int 4: 79-85.

12. Pothacharoen $P$, Teekachunhatean $S$, Louthrenoo W, Yingsung W, Ong-Cha S, et al. (2006) Raised chondroitin sulfate epitopes and hyaluronan in serum from rheumatoid arthritis and osteoarthritis patients. Osteoarthritis Cartilage 14 299-301.

13. Takahashi M, Naito K, Abe M, Sawada T, Nagano A (2004) Relationship between radiographic grading of osteoarthritis and the biochemical markers for arthritis in knee osteoarthritis. Arthritis Res Ther 6: R208-212.

14. Xiang $Y$, Sekine $T$, Nakamura $H$, Imajoh-Ohmi S, Fukuda $H$, et al. (2006) Fibulin-4 is a target of autoimmunity predominantly in patients with osteoarthritis. J Immunol 176: 3196-3204

15. Ashraf S, Walsh DA (2008) Angiogenesis in osteoarthritis. Curr Opin Rheumato 20: $573-580$ 
Citation: Savitskaya YA, Duarte C, Marín N, Téllez R, Alfaro A, et al. (2012) Identification of Circulating Natural Antibodies against Endogenous Mediators in the Peripheral Blood Sera of Patients with Osteoarthritis of the Knee: A New Diagnostic Frontier. J Mol Biomark Diagn 3:135. doi:10.4172/2155-9929.1000135

16. Askling J, Fored CM, Brandt L, Baecklund E, Bertilsson L, et al. (2005) Risks of solid cancers in patients with rheumatoid arthritis and after treatment with tumour necrosis factor antagonists. Ann Rheum Dis 64: 1421-1426.

17. Bhoola KD, Elson CJ, Dieppe PA (1992) Kinins--key mediators in inflammatory arthritis? $\mathrm{Br} J$ Rheumatol 31: 509-518.

18. Bonnet CS, Walsh DA (2005) Osteoarthritis, angiogenesis and inflammation. Rheumatology (Oxford) 44: 7-16.

19. Cheng ZJ, Vapaatalo H, Mervaala E (2005) Angiotensin II and vascular inflammation. Med Sci Monit 11: RA194-205.

20. Altman R, Asch E, Bloch D, Bole G, Borenstein D, et al. (1986) Development of criteria for the classification and reporting of osteoarthritis. Classification of osteoarthritis of the knee. Diagnostic and Therapeutic Criteria Committee of the American Rheumatism Association. Arthritis Rheum 29: 1039-1049.

21. Williams FM (2009) Biomarkers: in combination they may do better. Arthritis Res Ther 11: 130.

22. Wollheim FA (2003) Early stages of osteoarthritis: the search for sensitive predictors. Ann Rheum Dis 62: 1031-1032.

23. Bruyere O, Collette J, Kothari M, Zaim S, White D, et al. (2006) Osteoarthritis magnetic resonance imaging, and biochemical markers: a one year prospective study. Ann Rheum Dis 65: 1050-1054.

24. Cobankara V, Oztürk MA, Kiraz S, Ertenli I, Haznedaroglu IC, et al. (2005) Renin and angiotensin-converting enzyme (ACE) as active components of the local synovial renin-angiotensin system in rheumatoid arthritis. Rheumatol In 25: $285-291$

25. Khakoo AY, Sidman RL, Pasqualini R, Arap W (2008) Does the reninangiotensin system participate in regulation of human vasculogenesis and angiogenesis? Cancer Res 68: 9112-9115

26. Stoka V, Turk V (2010) A structural network associated with the kallikrein-kinin and renin-angiotensin systems. Biol Chem 391: 443-454.

27. Sharma JN, Buchanan WW (1994) Pathogenic responses of bradykinin system in chronic inflammatory rheumatoid disease. Exp Toxicol Pathol 46: 421-433.

28. Sharma JN (1991) The role of kinin system in joint inflammatory disease. Eur $J$ Rheumatol Inflamm 11: 30-37.

29. Lerner UH (1994) Regulation of bone metabolism by the kallikrein-kinin system the coagulation cascade, and the acute-phase reactants. Oral Surg Oral Med Oral Pathol 78: 481-493.

30. Joseph K, Kaplan AP (2005) Formation of bradykinin: a major contributor to the innate inflammatory response. Adv Immunol 86: 159-208.

31. Koch AE, Distler O (2007) Vasculopathy and disordered angiogenesis in selected rheumatic diseases: rheumatoid arthritis and systemic sclerosis. Arthritis Res Ther : S3.

32. Rahman MM, Bhoola KD, Elson CJ, Lemon M, Dieppe PA (1995) Identification and functional importance of plasma kallikrein in the synovial fluids of patients with rheumatoid, psoriatic, and osteoarthritis. Ann Rheum Dis 54: 345-350.

33. Uhl J, Singh S, Brophy L, Faunce D, Sawutz DG (1992) Role of bradykinin in inflammatory arthritis: identification and functional analysis of bradykinin receptors on human synovial fibroblasts. Immunopharmacology 23: 131-138.

34. Colman RW (2006) Regulation of angiogenesis by the kallikrein-kinin system. Curr Pharm Des 12: 2599-2607.

35. Heffelfinger SC (2007) The renin angiotensin system in the regulation of angiogenesis. Curr Pharm Des 13: 1215-1229.

36. Clapp C, Thebault S, Jeziorski MC, Martínez De La Escalera G (2009) Peptide hormone regulation of angiogenesis. Physiol Rev 89: 1177-1215.

37. Folkman J, Klagsbrun M (1987) Angiogenic factors. Science 235: 442-447.

38. Szekanecz Z, Koch AE (2005) Endothelial cells in inflammation and angiogenesis. Curr Drug Targets Inflamm Allergy 4: 319-323.

39. Szekanecz Z, Koch AE (2004) Vascular endothelium and immune responses: implications for inflammation and angiogenesis. Rheum Dis Clin North Am 30 : 97-114.

40. Avrameas S, Dighiero G, Lymberi P, Guilbert B (1983) Studies on natural antibodies and autoantibodies. Ann Immunol (Paris) 134D: 103-113.
41. Avrameas S, Ternynck T (1995) Natural autoantibodies: the other side of the immune system. Res Immunol 146: 235-248.

42. Baxendale HE, Johnson M, Stephens RC, Yuste J, Klein N, et al. (2008) Natura human antibodies to pneumococcus have distinctive molecular characteristics and protect against pneumococcal disease. Clin Exp Immunol 151: 51-60.

43. van Gaalen FA, Linn-Rasker SP, van Venrooij WJ, de Jong BA, Breedveld FC et al. (2004) Autoantibodies to cyclic citrullinated peptides predict progression to rheumatoid arthritis in patients with undifferentiated arthritis: a prospective cohort study. Arthritis Rheum 50: 709-715.

44. Konishi E, Kitai Y, Nishimura K, Harada S (2010) Antibodies to bovine serum albumin in human sera: problems and solutions with casein-based ELISA in the detection of natural Japanese encephalitis virus infections. Jpn J Infect Dis 63: $296-298$

45. Abu-Shakra M, Shoenfeld Y (2007) Natural hidden autoantibodies. Isr Med Assoc J 9: 748-749.

46. de Rycke L, Peene I, Hoffman IE, Kruithof E, Union A, et al. (2004) Rheumatoid factor and anticitrullinated protein antibodies in rheumatoid arthritis: diagnostic value, associations with radiological progression rate, and extra-articular manifestations. Ann Rheum Dis 63: 1587-1593.

47. Fleming SD (2006) Natural antibodies, autoantibodies and complement activation in tissue injury. Autoimmunity 39: 379-386

48. Silverman GJ, Grönwall C, Vas J, Chen Y (2009) Natural autoantibodies to apoptotic cell membranes regulate fundamental innate immune functions and suppress inflammation. Discov Med 8: 151-156.

49. Simón JA, Cabiedes J, Ortiz E, Alcocer-Varela J, Sánchez-Guerrero J (2004) Anti-nucleosome antibodies in patients with systemic lupus erythematosus of recent onset. Potential utility as a diagnostic tool and disease activity marker. Rheumatology (Oxford) 43: 220-224.

50. Skriner K, Hueber W, Süleymanoglu E, Höfler E, Krenn V, et al. (2008) AUF1 the regulator of tumor necrosis factor alpha messenger RNA decay, is targeted by autoantibodies of patients with systemic rheumatic diseases. Arthritis Rheum 58: 511-520.

51. Petitpierre S, Aubert V, Leimgruber A, Spertini F, Bart PA (2009) [Use of autoantibodies in clinical practice]. Rev Med Suisse 5: 823-831.

52. Quintana FJ, Cohen IR (2004) The natural autoantibody repertoire and autoimmune disease. Biomed Pharmacother 58: 276-281.

53. Schettino EW, Ichiyoshi Y, Casali $P$ (1996) Structure-function relation in natura and disease-associated human autoantibodies. In: Zanetti M, Carpa JD (Eds) The Antibodies. Harwood Academic Publishers, Amsterdam: 155.

54. Casali P, Schettino EW (1996) Structure and function of natural antibodies Curr Top Microbiol Immunol 210: 167-179.

55. Ehrenstein MR, Cook HT, Neuberger MS (2000) Deficiency in serum immunoglobulin (lg)M predisposes to development of IgG autoantibodies. J Exp Med 191: 1253-1258.

56. Elkon K, Casali P (2008) Nature and functions of autoantibodies. Nat Clin Pract Rheumatol 4: 491-498

57. George J, Shoenfeld Y (1996) Natural auto antibodies. In: Perer J, Shoenfeld Y: Autoantibodies. Amsterdam: Elsevier Science BV: 534-539.

58. Lacroix-Desmazes S, Kaveri SV, Mouthon L, Ayouba A, Malanchère E, et al (1998) Self-reactive antibodies (natural autoantibodies) in healthy individuals. J Immunol Methods 216: 117-137.

59. Suzuki K, Sawada T, Murakami A, Matsui T, Tohma S, et al. (2003) High diagnostic performance of ELISA detection of antibodies to citrullinated antigens in rheumatoid arthritis. Scand J Rheumatol 32: 197-204.

60. Lorber M, Kra-Oz Z, Guilbrud B, Shoenfeld Y (1995) Natural (antiphospholipid$\mathrm{PDH},-\mathrm{DNA}$ ) autoantibodies and their physiologic serum inhibitors. Isr $\mathrm{J}$ Med Sci 31: 31-35.

61. Song YW, Kang EH (2010) Autoantibodies in rheumatoid arthritis: rheumatoid factors and anticitrullinated protein antibodies. QJM 103: 139-146.

62. Madi A, Hecht I, Bransburg-Zabary S, Merbl Y, Pick A, et al. (2009) Organization of the autoantibody repertoire in healthy newborns and adults revealed by system level informatics of antigen microarray data. Proc Natl Acad Sci U S A 106: $14484-14489$ 
Citation: Savitskaya YA, Duarte C, Marín N, Téllez R, Alfaro A, et al. (2012) Identification of Circulating Natural Antibodies against Endogenous Mediators in the Peripheral Blood Sera of Patients with Osteoarthritis of the Knee: A New Diagnostic Frontier. J Mol Biomark Diagn 3:135. doi:10.4172/2155-9929.1000135

63. Mouthon L, Haury M, Lacroix-Desmazes S, Barreau C, Coutinho A, et al (1995) Analysis of the normal human IgG antibody repertoire. Evidence that IgG autoantibodies of healthy adults recognize a limited and conserved set of protein antigens in homologous tissues. J Immunol 154: 5769-5778.

64. Tauber Al (1994) The immune self: theory or metaphor? Immunol Today 15 134-136.

65. Schroeder HW Jr, Hillson JL, Perlmutter RM (1987) Early restriction of the human antibody repertoire. Science 238: 791-793.

66. Peng Y, Martin DA, Kenkel J, Zhang K, Ogden CA, et al. (2007) Innate and adaptive immune response to apoptotic cells. J Autoimmun 29: 303-309.

67. Veggiani G, Zuin J, Beneduce L, Gallotta A, Pengo P, et al. (2010) Combinatorial semisynthesis of biomarker-IgM complexes. J Biomol Screen 15: 1274-1280.

68. Hansson GK (2001) Immune mechanisms in atherosclerosis. Arterioscler Thromb Vasc Biol 21: 1876-1890.

69. Struglics A, Larsson S, Pratta MA, Kumar S, Lark MW, et al. (2006) Human osteoarthritis synovial fluid and joint cartilage contain both aggrecanaseand matrix metalloproteinase-generated aggrecan fragments. Osteoarthritis Cartilage 14: 101-113.

70. Abu-Shakra M, Shoenfeld $Y$ (1993) Introduction to natural autoantibodies. In: Shoenfeld Y, Isenberg D: Natural Autoantibodies. CRC Press: 15-33.

71. Bizzaro N, Tozzoli R, Shoenfeld Y (2007) Are we at a stage to predict autoimmune rheumatic diseases? Arthritis Rheum 56: 1736-1744.

72. Boes M, Schmidt T, Linkemann K, Beaudette BC, Marshak-Rothstein A, et al. (2000) Accelerated development of IgG autoantibodies and autoimmune disease in the absence of secreted IgM. Proc Natl Acad Sci U S A 97: 11841189.

73. da Mota LM, dos Santos Neto LL, de Carvalho JF (2009) Autoantibodies and other serological markers in rheumatoid arthritis: predictors of disease activity? Clin Rheumatol 28: 1127-1134.

74. Han JW, Lee KY, Hwang JY, Koh DK, Lee JS (2010) Antibody status in children with steroid-sensitive nephrotic syndrome. Yonsei Med J 51: 239-243.

75. Honsawek S, Tanavalee A, Sakdinakiattikoon M, Chayanupatkul M Yuktanandana P (2009) Correlation of plasma and synovial fluid osteopontin with disease severity in knee osteoarthritis. Clin Biochem 42: 808-812.

76. Jasin HE (1985) Autoantibody specificities of immune complexes sequestered in articular cartilage of patients with rheumatoid arthritis and osteoarthritis. Arthritis Rheum 28: 241-248.

77. Cooke TD, Bennett EL, Ohno O (1980) The deposition of immunoglobulins and complement in osteoarthritic cartilage. Int Orthop 4: 211-217.

78. Kerekes G, Szekanecz Z, Dér H, Sándor Z, Lakos G, et al. (2008) Endothelia dysfunction and atherosclerosis in rheumatoid arthritis: a multiparametric analysis using imaging techniques and laboratory markers of inflammation and autoimmunity. J Rheumatol 35: 398-406.

79. Ratcliffe A, Israel HA, Saed-Nejad F, Diamond B (1998) Proteoglycans in the synovial fluid of the temporomandibular joint as an indicator of changes in cartilage metabolism during primary and secondary osteoarthritis. J Oral Maxillofac Surg 56: 204-208.

80. Sakata M, Tsuruha JI, Masuko-Hongo K, Nakamura H, Matsui T, et al. (2001) Autoantibodies to osteopontin in patients with osteoarthritis and rheumatoid arthritis. J Rheumatol 28: 1492-1495.

81. Vynios DH, Tsagaraki I, Grigoreas GH, Samiotaki M, Panayotou G, et al. (2006) Autoantibodies against aggrecan in systemic rheumatic diseases. Biochimie 88: $767-773$

82. Ling SM, Patel DD, Garnero P, Zhan M, Vaduganathan M, et al. (2009) Serum protein signatures detect early radiographic osteoarthritis. Osteoarthritis Cartilage 17: 43-48.

83. Nell VP, Machold KP, Stamm TA, Eberl G, Heinzl H, et al. (2005) Autoantibody profiling as early diagnostic and prognostic tool for rheumatoid arthritis. Ann Rheum Dis 64: 1731-1736.

84. Izai M, Miyazaki S, Murai R, Morioka Y, Hayashi H, et al. (1992) Prorenin-renin axis in synovial fluid in patients with rheumatoid arthritis and osteoarthritis. Endocrinol Jpn 39: 259-267.

85. Meyer O, Semmache M, Cyna J, Mitrovic D, Ryckewaert A (1983) [Anti- collagen antibodies. Their detection in rheumatoid polyarthritis, chronic atrophic polychondritis and various chronic inflammatory rheumatism]. Rev Rhum Mal Osteoartic 50: 493-499.

86. Mollenhauer J, von der Mark K, Burmester G, Glückert K, Lütjen-Drecoll E, et al. (1988) Serum antibodies against chondrocyte cell surface proteins in osteoarthritis and rheumatoid arthritis. J Rheumatol 15: 1811-1817.

87. Monach PA, Benoist C, Mathis D (2004) The role of antibodies in mouse models of rheumatoid arthritis, and relevance to human disease. Adv Immuno 82: 217-248.

88. Savitkaya YA, Duarte C, Alfaro A, Marín N, Tellez R, et al. (2010) Isolation and characterization of circulating natural antibodies against endogenous mediators in the peripheral blood of patients with osteoarthritis of the knee and healthy individuals. Osteoarthritis and Cartilage: S207.

89. Savitkaya YA, Duarte C, Tellez R, Marín N, Morales E, et al. (2010) Identification of circulating natural antibodies against endogenous mediators in the peripheral blood sera of patients with osteoarthritis of the knee. Osteoarthritis and Cartilage: S30-S31.

90. Anitua E, Sánchez M, de la Fuente M, Azofra J, Zalduendo M, et al. (2009) Relationship between Investigative Biomarkers and Radiographic Grading in Patients with Knee Osteoarthritis. Int J Rheumatol 2009: 747432.

91. Bendtzen K, Svenson M, Jønsson V, Hippe E (1990) Autoantibodies to cytokines--friends or foes? Immunol Today 11: 167-169.

92. Coutinho A, Kazatchkine MD, Avrameas S (1995) Natural autoantibodies. Curr Opin Immunol 7: 812-818.

93. Goekoop-Ruiterman YP, de Vries-Bouwstra JK, Allaart CF, van Zeben D, Kerstens PJ, et al. (2005) Clinical and radiographic outcomes of four different treatment strategies in patients with early rheumatoid arthritis (the BeSt study): a randomized, controlled trial. Arthritis Rheum 52: 3381-3390.

94. Ritter K (1991) Affinity purification of antibodies from sera using polyvinylidenedifluoride (PVDF) membranes as coupling matrices for antigens presented by autoantibodies to triosephosphate isomerase. J Immunol Methods 137: 209-215

95. Robinson WH (2006) Antigen arrays for antibody profiling. Curr Opin Chem Biol 10: 67-72

96. KELLGREN JH, LAWRENCE JS (1957) Radiological assessment of osteoarthrosis. Ann Rheum Dis 16: 494-502.

97. Boyden SV (1966) Natural antibodies and the immune response. Adv Immuno 5: 1-28.

98. Janeway CA, Travers P (2005) Immunobiology: The Immune System in Health and Disease (Garland Science, New York).

99. Nielen MM, van Schaardenburg D, Reesink HW, van de Stadt RJ, van der Horst-Bruinsma IE, et al. (2004) Specific autoantibodies precede the symptoms of rheumatoid arthritis: a study of serial measurements in blood donors. Arthritis Rheum 50: 380-386.

100. Veihelmann A (2003) [The significance of immunology in orthopaedics today] Orthopade 32: 736-743.

101.Brüggemann M, Rajewsky K (1982) Regulation of the antibody response against hapten-coupled erythrocytes by monoclonal antihapten antibodies of various isotypes. Cell Immunol 71: 365-373.

102. Cohen IR (2007) Real and artificial immune systems: computing the state of the body. Nat Rev Immunol 7: 569-574.

103. Coutinho A, Kazatchkine MD (1994) Autoimmunity. Physiology and Disease. John Wiley, New York.

104. Lanzer WL (1987) Immunology for orthopedists. Arthroscopy 3: 141-151.

105. Xiang Y, Sekine T, Nakamura H, Imajoh-Ohmi S, Fukuda H, et al. (2004) Proteomic surveillance of autoimmunity in osteoarthritis: identification of triosephosphate isomerase as an autoantigen in patients with osteoarthritis. Arthritis Rheum 50: 1511-1521.

106. Zhao X, Okeke NL, Sharpe O, Batliwalla FM, Lee AT, et al. (2008) Circulating immune complexes contain citrullinated fibrinogen in rheumatoid arthritis. Arthritis Res Ther 10: R94.

107. Guilbert B, Dighiero G, Avrameas S (1982) Naturally occurring antibodies against nine common antigens in normal human sera. Detection, isolation, and characterization. J Immunology 128: 2779. 
Citation: Savitskaya YA, Duarte C, Marín N, Téllez R, Alfaro A, et al. (2012) Identification of Circulating Natural Antibodies against Endogenous Mediators in the Peripheral Blood Sera of Patients with Osteoarthritis of the Knee: A New Diagnostic Frontier. J Mol Biomark Diagn 3:135. doi:10.4172/2155-9929.1000135

Page 9 of 9

108. Konishi E, Shoda M, Ajiro N, Kondo T (2004) Development and evaluation of an enzyme-linked immunosorbent assay for quantifying antibodies to Japanese encephalitis virus nonstructural 1 protein to detect subclinical infections in vaccinated horses. J Clin Microbiol 42: 5087-5093.

109. Raiko I, Sander I, Weber DG, Raulf-Heimsoth M, Gillissen A, et al. (2010) Development of an enzyme-linked immunosorbent assay for the detection of human calretinin in plasma and serum of mesothelioma patients. BMC Cancer 10: 242.

110. Santos-Neto JR, Mezencio JM, Chagas AT, Michereff-Filho M, Serrão JE (2010) Use of serological techniques for determination of Spodoptera frugiperda(J E Smith) predators (Lepidoptera: Noctuidae). Neotrop Entomol 39: 420-423.

111. Tanaka Y, Komori H, Mori S, Soga Y, Tsubaki T, et al. (2010) Evaluating the role of rheumatoid factors for the development of rheumatoid arthritis in a mouse model with a newly established ELISA system. Tohoku J Exp Med 220: $199-206$
112. Tate J, Ward G (2004) Interferences in immunoassay. Clin Biochem Rev 25 105-120.

113. Jerne NK (1974) Towards a network theory of the immune system. Ann Immunol (Paris) 125C: 373-389.

114. Jerne NK (1967) [Various basic problems of current immunology]. Landarzt 43: $1526-1530$

115. Yurasov S, Nussenzweig MC (2007) Regulation of autoreactive antibodies Curr Opin Rheumatol 19: 421-426.

116. Zhou ZH, Zhang Y, Hu YF, Wahl LM, Cisar JO, et al. (2007) The broad antibacterial activity of the natural antibody repertoire is due to polyreactive antibodies. Cell Host Microbe 1: 51-61.

117. Visser H, le Cessie S, Vos K, Breedveld FC, Hazes JM (2002) How to diagnose rheumatoid arthritis early: a prediction model for persistent (erosive) arthritis. Arthritis Rheum 46: 357-365. 